\title{
Improved Micellar Dispersal of Dietary Lipid by Bile Acids during Replacement Therapy in Growth Hormone-deficient Children
}

\author{
J. RAINFE POLLY. " J. DARRFLL. SMITH, JOHN B. IHOMIPSON. ANI) J. ROIOMAN SFELY \\ Oklahoma Childre'n's Memorial Hospital. University of (Oklahoma He'alth Scie'nce's c'enter. and Veterans \\ Administratom Hospital, Oklahoma (its, oklahoma
}

\begin{abstract}
Summary
To date, no information is available on whether human growth hormone (hGH) exerts an influence on digestive processes in man. To test this, we studied the composition of the aqueous (micellar) phase during the digestion of two consecutive meals in growth hormone-deficient individuals and in control subjects, before and after replacement therapy with hGH.

Before treatment, the average micellar bile acid concentration was $5.0 \pm 0.6 \mathrm{mM}$ (normal adults and controls subjects: 6-15 $\mathrm{mM}$ ) during the first meal, and $3.5 \pm 0.9 \mathrm{mM}$ (normal adults and control subjects $5-10 \mathrm{mM}$ ) during the second meal. After 1 year of treatment, the mean micellar bile acid concentration increased to $9.7 \pm 1.0 \mathrm{mM}(P<0.02)$ during the first, and to $7.1 \pm 0.3 \mathrm{mM}(P<0.01)$ during the second meal. Concomitantly with an increased micellar bile acid concentration, micellar lipid increased as well (effect of treatment: (I) fatty acid, first meal $6.3 \pm 0.6 \mathrm{mM}$ to $13.0 \pm 0.7 \mathrm{mM}, P<0.001$; second meal $4.5 \pm 1.5 \mathrm{mM}$ to $8.5 \pm 0.3 \mathrm{mM}, P<0.05$; (2) monoglyceride, as percentage of total fatty acids: first meal 25 \pm 10 to $53 \pm 7, P<0.02$; second meal $31 \pm 7$ to $62 \pm 6, P$ 0.02).

Short term treatment (10 days) did not have an effect on the concentration of micellar bile acids and lipids in the control subjects. There was no significant difference in the physical state of bile acids and lipids between patients and control subjects before and after treatment.
\end{abstract}

\section{Speculation}

The digestion of dietary lipid involves a sequence of important steps: after emulsification, lipolysis generates fatty acids and monoglyceride, which require dispersal by bile acids (above their critical micellar concentration) for transport through the aqueous milieu to the membrane of the enterocyte. The "physiologic micellar concentration" of bile acids in the intestine during a meal for the efficient micellar dispersal of lipid is between 3 and $4 \mathrm{mM}$.

The increase of the intestinal micellar bile acid concentration from borderline to normal adult levels after replacement therapy with growth hormone could be explained as follows. The increased concentrations of bile acids in the intestine after treatment was the result of an increased hepatobiliary secretion of bile acids. This could have been effected by a growth hormonemediated increase of hepatic bile acid synthesis, or through increased storage capacity of the gallbladder. The latter is probably best explained by a growth hormone-stimulated secretin effect, rather than an effect of gallbladder emptying. Further, increased availability of bile acids for lipid digestion could also result from their improved intestinal conservation (absorption).

The clinical implications of the results reported in this study are indirect, but may point towards an interrelationship between hormonal stimulation and certain aspects of hepatobiliary function, which influence digestive processes.

In recent years, evidence has accumulated suggesting that hormones may influence digestive and/or absorptive processes in man and experimental animals. MeBrien et al. (16) observed steatorrhea in individuals with Addison's discase. Which was corrected by replacement therapy. Steatorrhea was also demonstrated in adrenalectomized rats (27). The fat malabsorption documented in hypoparathyroid patients reported by Miettinen and Perheentupa (18) was thought to be related to a decreased availability of bile acids in the intestinal lumen. Malabsorption of dectary lipid was observed in hypophysectomized dogs without structural abnormality of the je junal mucosa $(1+)$. By contrast. no fat malabsorption was seen in rats after hypophysectomy on two different dietary regimens $(25)$.

Occasionally. it was observed (4) that growth hormone-deficient individuals may have increased loss of fecal fat. the etiology of which has remained obscure. Since intestinal villous atrophy has never been observed in such patients. any increased fecal fat could be the result of fat maldignention and/or malabsorption. In analogy to hypoparathyroid patients (18), we considered the possibility that a decreased amount of bile acids during digestion could result in insufficient solubilization of lipolytic products. Hence. we decided to investigate intraluminal aspects of fat digestion. $i . e^{\prime}$. the efficiency of bile acid-mediated micellar dispersion of dietary lipid in growth hormone-deficient patients. To test this we studied the composition of the ayueous (micellar) phase during the digestion of two consecutive test meals in growth hormone-deficient individuals and in control subjects before and after replacement therapy with human growth hormone (29).

\section{PATIINTS AND METHOIDS}

PAIIINTS

All individuals who participated in this study were hospitalized in the Clinical Research center, after informed consent had been obtained. The investigations on patients and controls were approved after review of the study protocols by the Committee on Human Experimentation of the University of Oklahoma Healhh Sciences (enter. Oklahoma (ity. Ok.

There were three male and two female patients aged $14-18$ years with isolated growth hormone deficiency, and three control subjects, aged between 11 and 15 vears. Two of the latter were girls with Turner's syndrome and the third, a boy, had constitutional short stature. The ability to secrete growth hormone was tested in all individuals by the following methods: measurement of the serum growth hormone levels after insulininduced hypoglyecmia. after arginine infusion, and at night. 2 
hr after they had attained deep sleep. Although there was adequate secretion of growth hormone in the three control subjects. a totally inadequate secretion of growth hormone was observed in the growth hormone-deficient paticnts. The latter showed no deficieney of other pituitary trophic hormones, with the possible exception of gonodotropins and hence. the re ceived no other form of therapy. h(ill was given in the following dosage: 2 units three times a week for 10 days (patients and control subjects). thereafter 3 units/weck for 12 months (paticnts only).

\section{MI:JII()I)S}

Intubaton and Sampling of Jejunal (omtents. After an avernight fast. a single lumen polyvinyl tube (O) $2.5 \mathrm{~mm}$. II) 2.1 . mm) with a metal collecting olive at the tip was placed under fluoroscopic control to a point about $20 \mathrm{~cm}$ distal to the ligament of Treit\%. Thereafter. $300 \mathrm{ml}$ of a $110 \mathrm{ll}$ homogenized. liquid. corn oil-containing test meal of known composition (9). and containing polyethyleneglycol (Pl:(;) was ingested within 3-7 min. There was never a problem with retching or vomiting. The individuals were then placed in a semireclining position.

fejunal contents were obtatined by siphenage and were colkected for a period of $90 \mathrm{~min}$ after catch test meal. at a rate of approximately $0.5-1.0 \mathrm{ml} / \mathrm{min}$. The contents were heated immediately ex tive to $7\left(1^{\circ} \mathrm{e}\right.$ and kept at this temperature for 10 min to inactivate pancreatic lipase. Thereafter. the jejunal contents were pooled in three 3()$-$ min aliquots and kept at $37^{\circ}$ until ultracentrifugation. Which was done immediately after the end of the 9() -min sampling period. Between meals. the individuals pursued recreational activity during which time nothing was ingested except $200 \mathrm{ml}$ water. The second test meal was given in the carly afternom. 3-t hr after sampling from the first meal had finished. Amount and composition of the meal and sampling technigues were identical.

Determination of ph. The pH was determined in all 3(1-min pooled samples with a ply electrode (Radiometer (openhagen).

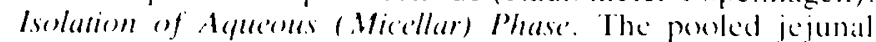
contents were well homogenized and centrifuged for + hr at $104.000) \times g$. at $37-38$ (Beckman-Spines 1.26 .513 preparative ultracentrifuge . After centrifugation. the alpuesous phase was sampled by piercing the tube with a needle and about 70); of the aqueous phase wats drawn into a calibrated syringe. A rather large sample of the micellar phase was aspirated in order (1) aroid sedimentation artifacts. which hate been observed after prolonged $(12 \mathrm{hr})$ centrifugation (21). ()casionally slight turbidity of the micellar phase was observed. which was thought to be due to mesophasic monoglyceride (7). The bile ateds and lipids were extrateded from the alqueous phatse with minor modificattions as described (16).

Determinatom of Micellar Bile' leid and Lipid. Bile acids: The ethanolic phase was evaporated to dryness. and the residue dissolved in a measured amount of spece grade methanol. ()ne aliquot was used for bile acid determination by the 3-hydroxysteroid dehydrogenase methes (1.3). The ratio of glveine to taturine conjugates. as well as the ration of dihydroxy to trihydrox! hile acids was determined by the eneymatic method after separation of bile aciels by thin laver chromategraphy (6). The coefficient of variation between replicate analyses was consistently below 3'i.

fanty acids and monoghereride: Thin laver chromatograms of the aleferous phase lipid extratets discloned manls fatts acids. monoglyecride. and cholesterol. with negligible amounts of diand triglyceride. The lipid extract wats dissoleded in acetence and one aliguot "as titrated directly as nonglycerol-bound fatty acid. Another aliquet was subjected to mild alkaline hudrolvsis. with subseyuent extratetion and titration as glverol-bound fatty acid. The difference between the values of tatte actd determination before and after hodrolsis was considered chicfls monoglyecride fatty atcid. The coefficient of vatiation between duplicate determinations was less than $+"$ ",
Phospholipids: Phospholipids ucre extracted from the micellar phase with chloroform-methanol (2:1), and determined by a micromethod $(s)$.

Physical State of lipids. To determine the physical state of bile acids and fatty acids present in the aqueous phase. bile acids and total fatty acids were determined in the unspun homogenised intestinal contents and in the aqueous phase to arrive at the percentage of bile atcid and fatty acid in solution.

\section{ANAIYSH:S}

Pl: ( was defermined turbidimetrically (12). All intraluminal indices were corrected for dilution. There was no significant difference of Pl: (i concentration in spun and unspun samples. Peroral suction biopsies (Pediatric (rosby-Kugler capsule. (o)llege Park Instruments. (ollege Park. Mo.) Were done in patients and control subjects to rule out morphologic changes of the villous architecture. (ias-liguid chromatography of bile acid methylester-atetates was done using $2.5 \%$ ( $)^{\prime}-17$ on $\mathrm{AW}^{\prime}$ I) M1 S (ias-chrom () (Applicd Science Laboratories. State (ollege. Pa.). Statistical analises were done using the rank sum test (28). Stool fat balance studies could not be performed. since prolonged hospitalization was unaceptable. as most individuals would have had to discontinue school for such studies.

\section{RI:SUITS}

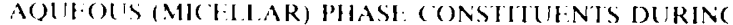 DICIESTION}

Patients (Table l). During treatment. all patients except one (.IH) responded well to exogenous h(iH with a good acceleration of height velocits (20)).

l'ariation befween meals: It has been estimated that during the collection of intestinal contents during the first meal. Less than $5 \%$ of the circulating bile aceid mass has been aspirated. This is unlikely to hate had a significant effect on intraluminal concentrations of bile acids during the second meal.

In general. there was a decrease of aquerous phase bile acids and lipids from the first to the second meal. Only once was there a significant decrease of bile acid concentration from the first to the second meal in the four growing patients. 10 dass after treattment. As in the control groups, before and after treatment with heith. the concentration of ayueous phase fatty acid decreased during the digestion of the second meal. whereas the percentage of monoglyceride increased.

Influence of treatment: The concentrations of jejunal ayueous phase bile acids during the two test meals in patients. normal adults (19). and control subjects hefore and after treatment are presented in figures 1 and 2. Treatment with heill led to a consistent increase of bile acid and fatty acid in the ayueous phatse. This increatse wats more conspicuous during the second meal. Before treatment. the concentration of bile acid and fatty acid in patients were lower than in control subjects $(P<0.02)$. but this defference was nearly equalized after + months of therapy with beill. Alter 12 months of therapy the concentration of hile acids and fatty acids, as well as the percentage of monoglyceride tatty acid. nearly doubled. and these changes "lere significant ( Iable 1 ).

(oncomitant with improved ayueous dispersal of dictary lipid during treatment. the fration of nonacueous phase lipid decreased. whereas the amount of total lipid in the intestinal lumen remained fairly constant during the two meals with little variation from individaal to individual. Although a statistically significant decrease of the means for phospholipids during treatment was obtained. an cxact interpretation of these changes cannot be made, as biliary phospholipid secretory rates wero not meiasured.

Patichl ItI (Table 2): Since this pationt did not show ans response to heit as measured by an increase in height velocity. the values of the aqueses phase lipids are presented separated for comparison with the groming patients presented in lable $i$. 
Table 1. Patients $(n=4)$ : Bile acids and lipids in the aqueous phase during digestion of twe consecutive test meals (me'an \pm SE)'

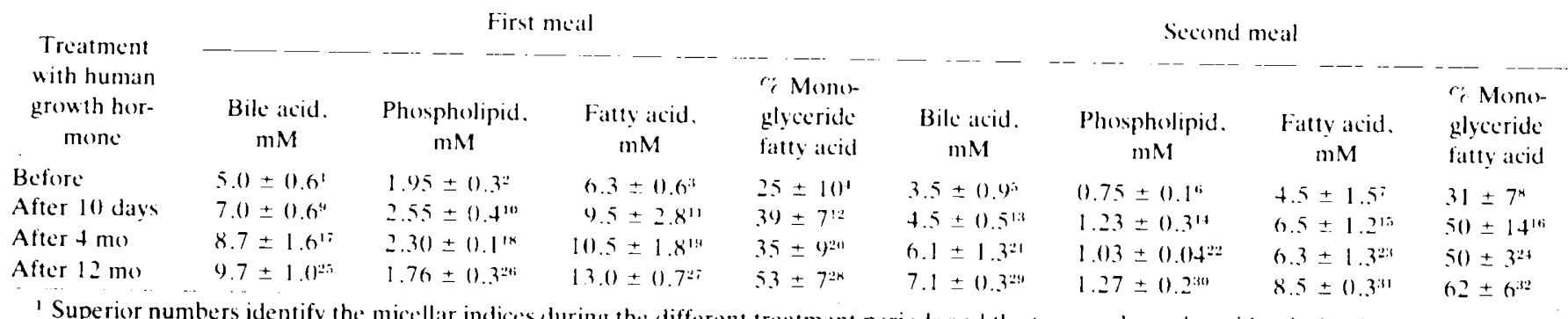
'Superior numbers identify the micellar indices during the different treatment periods and the two meals, and are identical to italic numbers in the
table, below.

Statistically significant differences of the me'ans

Bile acid
Fatty acid
9 is. $I .3(P<0.02 \downarrow)$

\% Monoglyceride fatty acid

Phospholipid

$$
\begin{aligned}
& 2 \text { is. } 6(P<0.02 \downarrow) \\
& 10 \text { is. } 14(P<0.05 \downarrow) \\
& 18 \text { is. } 22(P<0.001 \downarrow)
\end{aligned}
$$

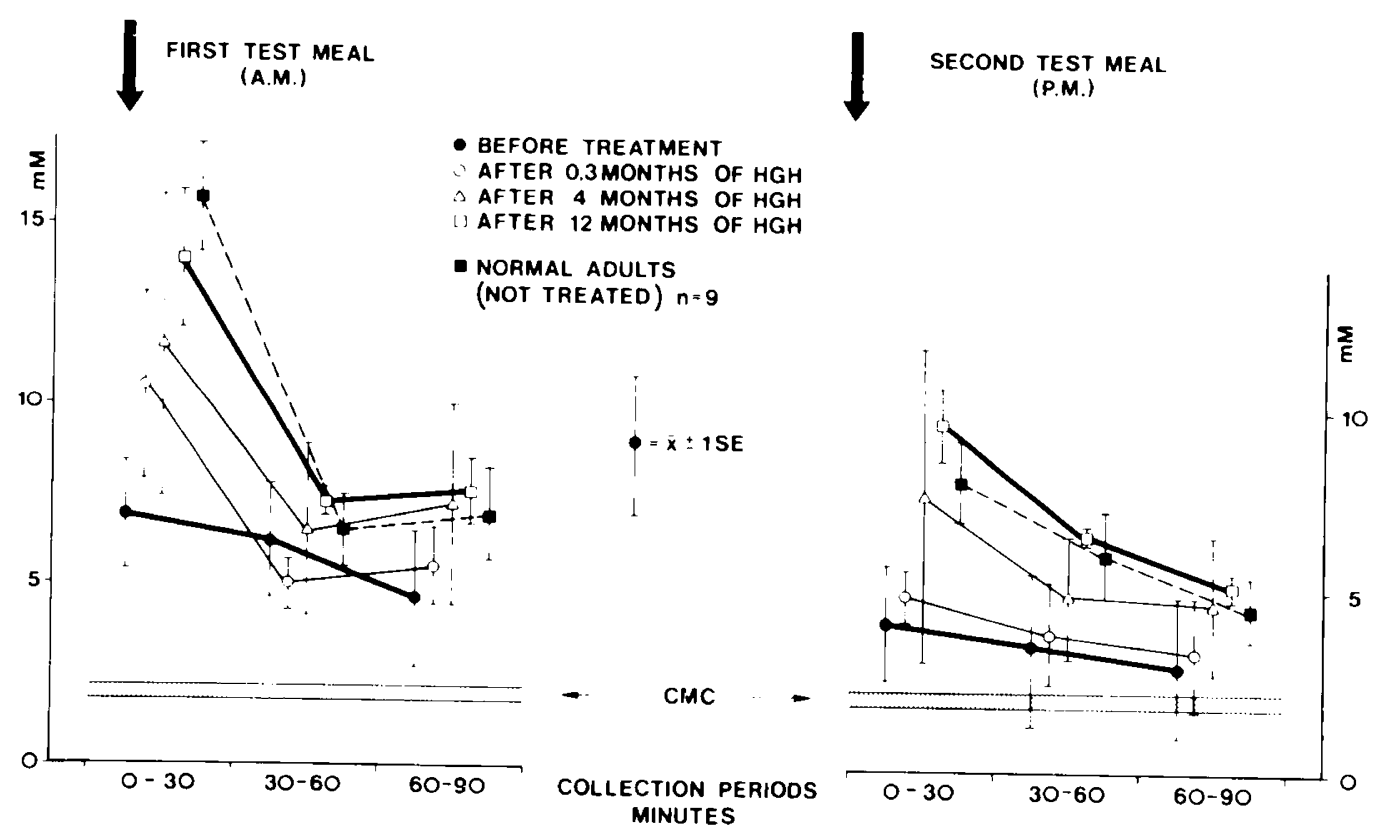

Fig. 1. Intraluminal concentration of adguecous phase bile acids after two sequential test meats in growth hormonc-deficient individuals $(n=4)$ and in healthy adults. (NIC: critical micellar concentration.

Only after 1 year of treatment was there a modest increase in the concentration of micellar bile acid and fatty acid. This increase has not been as great as compared with patients presented in Table 1 . and was only noted affer the first. but not during the second meal.

Control Subjects. There was essentially no change of bile acid. phospholipid. fatty acid concentration. and percentage of moneglyceride fatty acid between the first and second meal. Short term treatment with $\mathrm{h}$ GH had little influence on the composition of the aqueous phase lipids. It was of interest. however, to see that. although the concentration of fatty acid was less during the second meal. that of fatty acid derived from monoglyecride increased.

\section{PHYSICAI. STATE OF BILE: ACIDS AND IUPIDS}

During the digestion of both meals, most bile acids ( $84-$ $98 \%$. first meal, 78-96\% second meal) and a considerable amount of fatty acids (39-60)" first meal. 26-44\%" second meal) were in solution. There was no significant difference between patient and control groups.

\section{INTRALUMINAL pH}

Before treatment. jejunal pH during the first meal in patients was $6.3 \pm 0.06$. Whereas in the control subjects it was $6.5 \pm$ $0.04(P<0.005)$. During the second meal it was $6.3 \pm 0.05$ for paticnts and $6.5 \pm 0.05$ for control subjects $(P<0.005)$. 


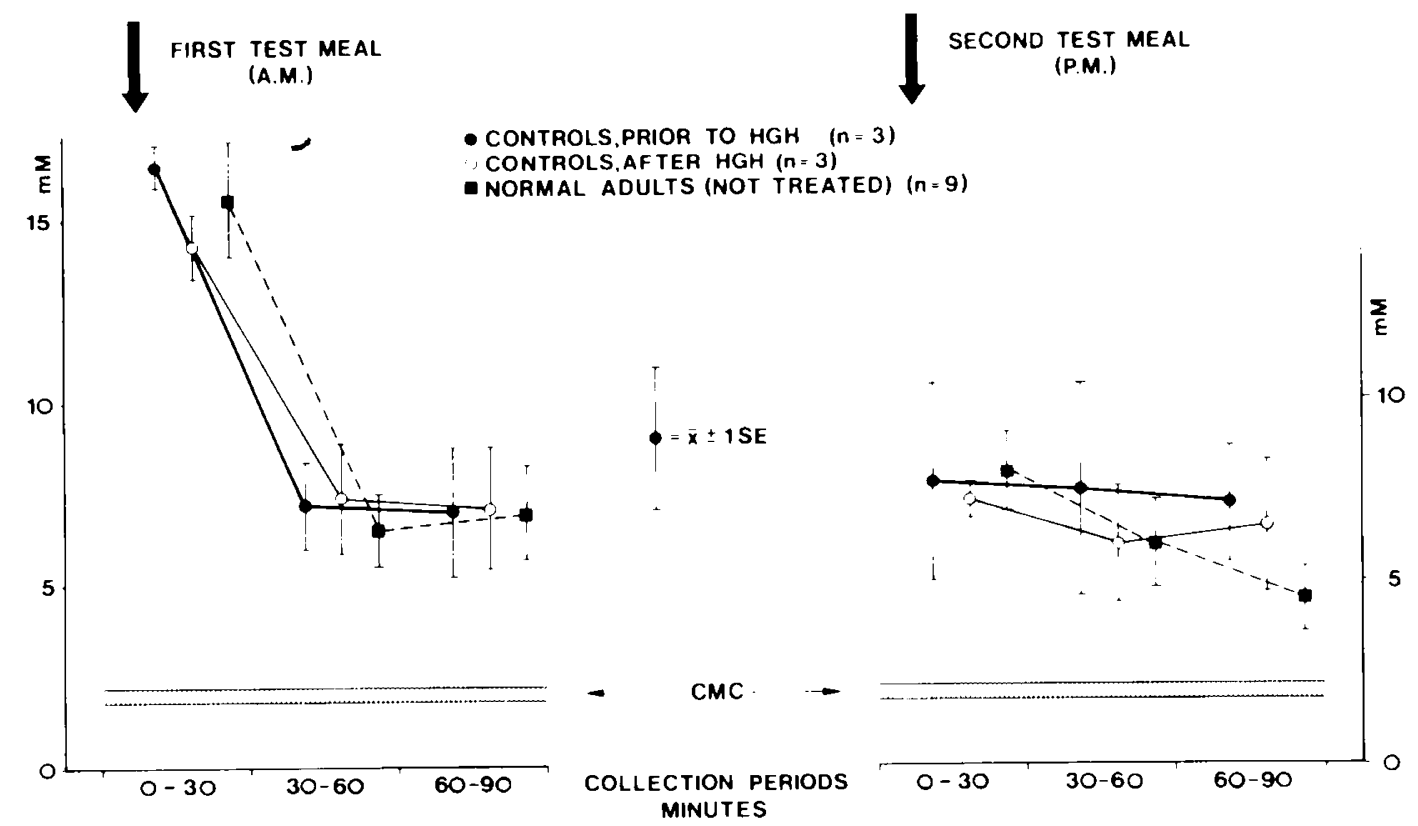

Fig. 2. Intrableminal concentration of ayucous phase bilc acids after two sequential test meak in control subjects of short stature and in healthy adults. Influence of human growth hormone $(2$ units day $\times 10)$. ( NIC: critical micellar concentration.

Table 2. Paticht JH: Bile acids and lipids in acpueous phase during digestion of awo consecutive te'st meals

\begin{tabular}{|c|c|c|c|c|c|c|c|c|}
\hline \multirow[b]{2}{*}{$\begin{array}{l}\text { Treatment } \\
\text { with hCilf }\end{array}$} & \multicolumn{4}{|c|}{ First meal } & \multicolumn{4}{|c|}{ Second meal } \\
\hline & $\begin{array}{c}\text { Bile acid. } \\
\mathrm{mM}\end{array}$ & $\begin{array}{c}\text { Phospholipid. } \\
\text { mM }\end{array}$ & $\begin{array}{l}\text { Fatty acid. } \\
\mathrm{mM}\end{array}$ & $\begin{array}{l}\because \text { Monoglycer- } \\
\text { ide fatty acid }\end{array}$ & $\begin{array}{l}\text { Bile acid. } \\
\text { mil }\end{array}$ & $\begin{array}{l}\text { Phospholipid. } \\
\mathrm{mM}\end{array}$ & $\begin{array}{l}\text { Falty acid. } \\
\mathrm{mM}\end{array}$ & $\begin{array}{l}\text { " Monoglycer- } \\
\text { ide fatty acidl }\end{array}$ \\
\hline Before & 4.9 & 1.78 & 5.9 & 21 & 3.1 & 0.83 & 7.11 & .31 \\
\hline After 10 days & 3.8 & 1.1 .3 & 2.6 & & 3.0 & 0.95 & 2.5 & \\
\hline After $t$ mo & 3.7 & 1.39 & 5.4 & 19 & 2.3 & 0.51 & +.1 & 26 \\
\hline After $12 \mathrm{mo}$ & 7.9 & 1.85 & 7.9 & 20 & +.3 & 0.95 & 5.6 & 6 \\
\hline
\end{tabular}

'Human growth hormone.

Table 3. Comtrol subjects $(n-3)$ : Bile acids and lipids in aqueous phase during digestion of ato consecutive test me'als $(m e a n \pm S E)^{1}$

\begin{tabular}{|c|c|c|c|c|c|c|c|c|}
\hline \multirow[b]{2}{*}{$\begin{array}{l}\text { Treatment } \\
\text { with h(jH: }\end{array}$} & \multicolumn{4}{|c|}{ First meal } & \multicolumn{3}{|c|}{ Second meal } & \multirow[b]{2}{*}{$\begin{array}{l}\text { Monoglyceride } \\
\text { fatty acid }\end{array}$} \\
\hline & $\begin{array}{c}\text { Bile acid, } \\
\mathrm{mM}\end{array}$ & $\begin{array}{c}\text { Phospholipid. } \\
\mathrm{mM}\end{array}$ & $\begin{array}{c}\mathrm{mM} \\
\mathrm{mM}\end{array}$ & $\begin{array}{l}\Rightarrow \text { Monoglyceride } \\
\text { fatty atcid }\end{array}$ & $\begin{array}{c}\text { Bilc acid. } \\
\mathrm{mM}\end{array}$ & $\begin{array}{c}\text { Phospholipid. } \\
\mathrm{mM}\end{array}$ & $\begin{array}{c}\text { Fatty acid. } \\
\mathrm{mM}\end{array}$ & \\
\hline & $10.8+1.3$ & $2.48 \pm 0.3$ & $9.3 \pm 0.9$ & $18 \pm 10$ & $7.7 \pm 2.5$ & $1.10 \pm 0.3$ & $6.3 \pm 0.7$ & $34 \pm 1.3$ \\
\hline After 10 days & $11.2 \pm 1.2$ & $2.05 \pm 0.7$ & $10 \pm 3.7$ & $22 \pm 11$ & $7.3+1.3$ & $1.14 \div 0.0 .3$ & $5.7 \pm 0.9$ & $+2 \pm 12$ \\
\hline
\end{tabular}

1 No significant differences of the means of bile acids, etc.. between first meal and second meal, without or with treatment.

"Human growth hormone.

This difference could have been due to a relative increase of $\mathrm{H}$ ions or a relative decrease of $1 \mathrm{l}\left(\mathrm{C}_{3}\right.$ jons in patients. Throughout treatment. the pH remained essentially unchanged in patients and control subjects.

The ph had little influence on the physical state of bile acid in the range between 5.9 and 7.5 . However. a moderate decrease of bike acid in solution was found in an occasional sample with $\mathrm{pH}$ of less than 5.7 , whereas only $60-70 \%$ of total bile acids were in the ayueous phase.

\section{RELATIONSHIPS BHETWEEN AQULOUS PHASE BILE ACIDS.} PHIOSPHOLIPIDS, AND FATTY ACIDS

Since conjugated bile acids above the critical micellar concentration for a mixed bile acid solution $(\approx 2 \mathrm{mM})$ disperse polar and nonpolar lipids in an aqueous solution at physiologic pH during digestion. it was of interest to look at the relationship between micellar solvent (bile acid and phospholipid) and micellar solute (fatty acid). These relationships are presented in Figure 3. showing a good correlation $(r=0.81)$ between these indices. When only micellar bile acid was plotted against micellar lipid, the correlation was not as good $(r=0.6 .3)$.

RATIOS OF (ILYCINF: TO TAURINE CONJUGATID BILE: ACIDS (G/T RATIOF ANI) DIHYDROXY TO TRIHYDROXY BIL. ACIDS

Treatment with growth hormone did not induce persistent changes of these indices. With the exception of patient $R N$. who showed a consistent decrealse in the $(\mathrm{s} / \mathrm{T}$ ratio $(1.4 \mathrm{to} / .0)$ and in the ratio of dihydroxy to trihydroxy bile acids (1.2 to 1.0$)$ during treatment. These findings are probably accidental. 


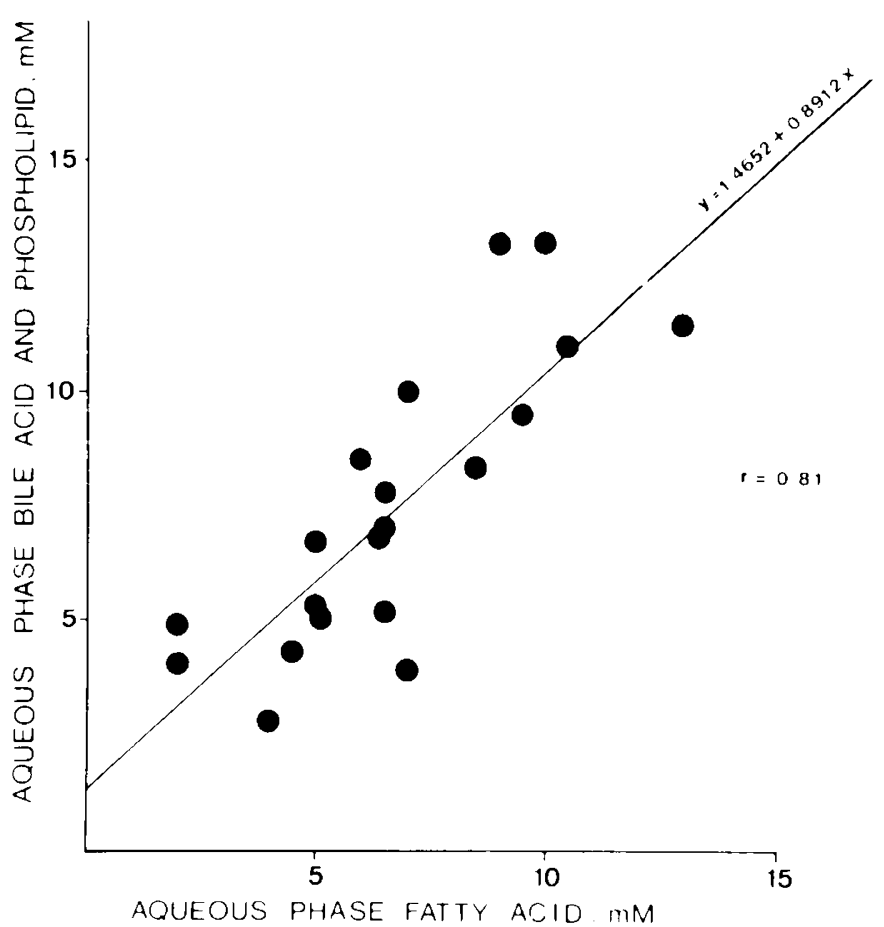

Fig. 3. Relationship between aqueous phase hile acid and phospholipid and fatty acid during digestion.

\section{SECONDARY BILE: ACIIDS}

The perentage of secondary (deoxycholate. lithocholate) and tertiary (ursodeoxycholate) bile acids remained essentially unchanged in three of the four patients who responded to growth hormone. However, in patient RN, there was a significant and persistent decrease of these bile acids from 19\% to $7 \%$ during treatment with growth hormone. After cessation of treatment. the perentage of secondary bile acids increased again to $10 \%$.

\section{SMALI. INIKSIINAL BIOPSII:S}

No structural abnormalities or changes could be elicited by light microscopy in either patients or control subjects before and after replacement therapy.

\section{DISCUSSION}

Efficient absorption of dietary lipid is dependent on efficient dispersal of fatty acid and monoglyeeride in bile acid micelles for transport to the intestinal mucosa (11). The physiologic micellar concentration of bile acids required for efficient lipid dispersal in vivo is probably between 3 and $+\mathrm{mM}(1.15)$.

Data presented in this study demonstrated increases in the concentration of aqueous (micellar) phase bile acids and fatty acids in the jejunum during digestion of two sequential meals in four of five patients treated with hGH. Since hGH was the only variable. there is a strong suggestion that these increases were effected by hoH.

Long term treatment with exogenous hGH at low physiologic dose's ( 3 units/week) led to a consistent increase of the concentration of aqueous phase bile acids. and this was particularly noticeable during the second meal. After 1 year, the values obtained during the first as well as during the second meal were indistinguishable from those of healthy adults (19) or the three control subjects. Consonant with the increase of the bile acid concentration in the aqueous phase, there was a rise in the total concentration of fatly acid in the aqueous phase. This was obviously the result of an improved and more efficient micellar dispersion of fatty acids and monoglyceride by bile acids, which were available in the intestine.
To explain the increased concentration of bile acids in the intestine in patients after replacement therapy, several possibilitics exist. (l) Increased hepatic synthesis of bile acids with conseguent increased hepatobiliary secretion is possible. It is not known whether growth hormone has a direct or indirect (viat the somatomedines) influence on cholesterol $7 \alpha$-hydroxylase, the rate-limiting enzyme for hepatic bile acid biosynthesis (24). In the hypophysectomized rat (2, 3) bile acid synthesis rates decreased hecause of a decreased turnover of primary bile acids. $i$.e.. cholic and chenic acids. without changes in pool sizes. (2) hGH may have increased bile acid secretion irrespective of any influence on bile acid synthesis. either by more efficient gallbladder emptying or by an increased gallbladder storage capacity (secretin effect). (3) Concentration of bile acids during the second meal after treatment could be explained also by their more efficient intestinal conservation. However. no information exists about whether growth hormone exerts an influence on the absorption of bile acids in the intestine. The decrease of secondary bile acids in patient RN may indicate decreased exposure of bile acids to bacteria because of improved absorption.

Polar lipids such as fatty acids and monoglyceride are efficiently dispersed by bile acids above a certain concentration (critical micellar concentration). In vitro. the critical micellar concentration for a mixed bile acid solution is in the vicinity of $2 \mathrm{mM}$ (11). In vive, the bile acid concentration needed for adequate micellar dispersal of dietary lipid is higher, and 3 to 4 $\mathrm{mM}$ seem to be required in adults (1) and newborns (15). A bile acid concentration of $+\mathrm{mM}$ was not always reached by three of the four growing patients during the digestion of the second meal before and after short term replacement therapy. Concomitant with the lower concentration of ayueous phase bile acids. the amount of fatty acids in growth hormone-deficient patients was also lower when compared with the control subjects, healthy adults (19), or healthy young children $(22,23)$.

Studies in model systems have demonstrated that phospholipids. Which are also amphiphiles, are capable of swelling the bile acid micelle (5). enhancing their solubilizing properties. The role of endogenous phospholipid during digestion of dictary lipid is still uncertain. hut is probably of importance (17). In the present study. the correlation between combined bile acid and phospholipid and fatty acids in the aqueous phase was much better than between bile acids and fatty acids alone. suggesting that phospholipids do indeed contribute towards more efficient dispersal of dietary lipid.

It would have been preferable to have had digestive studies after three consecutive meals, as was done in patients with bile acid deficiency after ileal resection (26). This way, a "decompensated" state with regard to intraluminal digestive events in growth hormone-deficient patients would have become more apparent.

Although this study did not prove an influence of hGH on fat absorption, an improvement of intraluminal bile acid dispersal of dietary lipid was obvious. It was unfortunate not to have been able to compare results of the digestive studies with fecal fat balances. because, for reasons stated above. We were not able to hospitalize patients for the period of time required to do proper fecal fat balance studies.

The clinical implications of the results reported in this study are indirect and might be viewed in the interrelationship between hormonal stimulation and hepatobiliary function which influences digestive processes.

\section{CONCLUSION}

To test the influence of replacement therapy in growth hormone-deficient individuals on micellar dispersion of dictary lipid. analyses on the composition of the atyueous (micellar) phase were done in five growth hormone-deficient patients aged 14-18 years, and in three control subjects aged 11-15 years during digestion of two consecutive test meals. Studies 
were done before treatment and after short term and long term treatment with hCiH

Before therapy with heit. the concentration of jejunal acueous phase bile acids was significantly lower in the patients as compared with the control subjects, particularly during the second meal. Consonant with low aqueous phase bile acid concentrations, there were also decreatsed amounts of lipid in solution.

Although hoit had no influence on the composition of the aqueous phase during digestion in the control subjects. significant increases of ayuerous phase bile acids and lipids were observed in four of the five growth hormone-deficient patients after continued treatment with holl. After 1 year of treatment. ayueous phase bile acids and fatty acids were equal to those of the control subiects and normal adults.

\section{RHFHRENCES AND NOTIS}

1. Badley, B. W. D.. Murphy, (;. M. Bouchier, 1. A. D.. and Sherleck, S Diminished miccllar phase lipid in paticnts with chronic non alcoholic live discase and steatorrhea. (iastroenterology, 58: 781 (1970).

2. Beher. W. T.. Beher. M.-F... and Semenuk, (i.: The effect of pituitary and thyroid hormones on bile acid metabolism in the rat. Metabolism, $15: 181$ (1969).

3. Beher, W. T., Rato. B. Beher, M. F... and Bertasius, J.: Bile acid synthesis in normal and hypophysectomized rats. A rate study using cholestyramine. Proc. Soc. Exp. Biol. Med.. 124: 1193(1967).

4. Blizzard, R. M.: Personal communication.

5. Bourges. M.. Small. D. M.. and Dervichian. 1). (i.: Biophysics of lipid associations. III. The quarternary systems lecithin-bile salt-cholesterol-water. Biochim. Biophys. Acti, 144: $189(1967)$.

6. Bruusqatad. A.: Quantitative determination of the major 3-hydroxy bile acids in biological material after thin-layer chromatographic separation. Clin. Chim. Acta, 28: $495(1970)$

7. Dreher K D Schulman, J and Hofmann. A. F.: Surface chemistry of the monoglyceride-bile salt swem: Its relationship to the function of hile salts in fat absorption. J. Coll. Interf. Sci.. 25: 71 (1967)

8. Gerlach, E... and Deuticke, B.: Eine einfache Methode zur Mikrobestimmung von Phosphat in der Papierchromatographie. Biochem. Z.. 337: 479 $(196.3)$.

9. Go, V. L. W., Poley, J. R., Hofmann, A. F. and Summerskill, W. H. J.: Disturbances in fat digestion induced hy acidic jejunal $\mathrm{pH}$ due to gastric hypersecretion in man. (iastroenterolegy, 58: 0.38 (197(1).

10. Hofmann, $A, F$ and Borgstrom, $B$. The intraluminal phase of fat digestion in man: The lipid content of the micellar and oil phases of intestinal content obtained during fat digestion and absorption. J. (lin. Invest.. 43: $247(1964)$

11. Hofmann, A, F. and Small, D. M.: Detergent properties of bile salts: Correlation with physiological function. Ann. Rev. Med.. 18:333 (1967)

12. Hyden, $S$.: A turbidimetric method for the determination of higher polyethylene glycols in biological materials. Ann. Roy. Agr. Coll. (Sweden), 22: 139 (1955)

13. Iwata, $T$. and Yamasaki, $K$ : Enzymatic determination and thin-layer chromatography of hile acids in blood. J. Biochem.. 50: 424 (1964).
14. Jacobson, E. D., Magnani. I. J., Mc(laskey. E. B., and Kallal. I. J.: Some effects of hypophysectomy on gastrointestinal function and structure. (jut, 5: $473(1964)$.

15. Latry, $U$.: Relation of duodenal bile acid concentration to coefficient of fat absorption. Cited by: J. B. Watkins: Bile acid metabolism and fat ahoorplion in newborn infants. Pediat (lin. N. Amer. 2l: 501 (1974)

16. McBrien, D. J.. Jones, R. V.. and Creamer. B.: Steatorrhocal in Addison's disease. Lancet, $i$ : 25 (196.3)

17. Mansbach. C. M. II, Cohen. R. S., and leff, P. B: lsolation and propertie of the mixed lipid micelles present in intestinal content during fat digestion in man. J. Clin. Invest., 56: 781 (1975).

18. Miettinen, 1. A., and Perheentupa, J.: Bile salt deficiency in fat malahsorption of hypoparathyroidism. Scand J. Lab. (Cin. Invest., /16: 36 (1471)

19. Poley. J. R.. and Hofmann. A. F.: Role of fat maldigestion in pathogenesis of teatorthea in ileal resection: Fat digestion after two sequential test meals with and without cholestyramine. (jastroenterology. 71: $38(1976)$.

211. Poley. J. R. Smith, J. D. Thompson, J. B.. and Seely. J. R.: Alterations in the concentration of cholesterel in hile after administration of human growth hormone. Pediat. Res., 8: $7111(1974)$.

21. Porter. H. P.. and Saunders, D. R.: Isolation of the aqueous phase of human intestinal contents during digestion of a fatty meal. (jastroenterology, of). 497 (1971).

3 Ricour. (C., and Rey. J.: Study of the oil and micellar phases during fat digestion in the normal child Rev. Fur. Ftud. (Clin. Biol. 15: 287 (197(1)

23. Ricour, $C^{\prime}$. and Rey. J.: Study on the hydrolysis and micellar solubilization of fats during intestinal perfusion. I. Results in the normal child. Rev. Har Etud ('lin. Biol., /7: 172 (1972)

24. Shefer S Hauser S Bekersky, L., and Mosbach F H. Biochemical site of regulation of bile acid biosynthesis in the ratt. J. L ipid Res.. /1: $4(14$ (1970).

25. Somkin, S. A., and Levitan, R.: Effect of hypophysectomy on fat absorption in the rat. Amer. J. Dig. Dis., 13:743 (1968).

20. Van Doest B W Fordtran, J S. Morawski, S. G.. and Wilson, J. D.: Bile salt and micellar fat concentration in proximal small bowel contents of ilecetomy patients. J. Clin. Invest., 47: $1314(1968)$

27. Watson. W. C., and Murray, E.: Fat digestion and absorption in the adrenalectomized rat. J. Lipid Res.. 7: 236 (1966)

28. Wilcoxon, F and Wilcox, R. A.: Some rapid approximate statistical proceJures. Lederle Lahoratories. Pearl River. New York.

29. The h(jll was supplied by the National Pituitary Agency (NIAMI)D and American (ollege of Pathologists).

30 The authers wish to thank Drs. A. F. Hofmann and J. Rey for helpful suggestions and gentle criticism: Ms. Sandra Matsenbaugh and Ms. Jane Drake for excellent technical assistance; Mts. F. Krais for the typing of the manuscript.

31. This work was supported in part by Public Health Service (jrant no. RR-62 from the Clinical Research Centers Branch. National Institutes of Health: and by Veterans Administration Part I Designated Research Funds.

32. The present address of Dr. J. D. Smith is: Hest Virginia University Schorol of Medicine. Department of Pediatrics, Medical center, Morgantewn. W. Va. 265016 .

33. The present address of Dr. J. B. Thompson is: The Liniversity of North Daketa School of Medicine. Department of Medicine. North F:lm. 21s Ave. Fargo, ND $5 \times 107$.

34. Requests for reprints should be addressed to: J. R. Poley, M. D.. Zentrum tiir Innere Medizin und Kinderheilkunde. Kinderklınik der Universitat Lilm. Prittuitestrasse 4.3.7906) lllm (Donau) Germany.

35. Received for publication Fethruary 2, 1977

36. Accepted for publication April 12. 1977. 